\title{
Percepções sobre a sala de aula de língua estrangeira: uma visão global e êmica
}

\author{
Andréa Machado de Almeida Mattos \\ Universidade Federal de Minas Gerais
}

\section{Abstract}

This paper reports on a study of a pre-service English teacher and her perceptions about her own classroom. The research design was based on theoretical and empirical studies about classroom research and about the FL teacher, adopting an interpretivist and emic perspective. The main objective of the research was to search for a global understanding of how the FL teacher interprets the events in the classroom, using retrospective interviews as the main data collection instrument. The content of these interviews was categorized, leading to the expansion of Richards' (1998) reflective categories. The results of analysis led to a global view of the informant's perceptions of her classroom. 
"Language teaching and language teacher education have long been an 'unstudied problem' ..."

(FREEMAN, 1996b, p. 374)

\section{INTRODUÇÃO}

$\mathrm{E}$ ste trabalho relata uma pesquisa que investigou uma professora de inglês em formação e suas percepções sobre sua sala de aula a partir de seu próprio ponto de vista. O desenho da pesquisa baseou-se em estudos teóricos e empíricos sobre pesquisa em sala de aula e sobre o professor de LE, adotando uma visão interpretativista e êmica. O objetivo principal da pesquisa foi buscar, através da reflexão, uma compreensão global sobre como o professor de LE interpreta sua sala de aula e os eventos que nela acontecem, utilizando entrevistas de retrospecção como principal instrumento para coleta de dados. O conteúdo dessas entrevistas foi categorizado, expandindo as categorias reflexivas de RICHARDS (1998). Os resultados da análise levaram a uma visão global das percepções da informante sobre sua sala de aula.

\section{AS BASES TEÓRICAS}

Durante várias décadas, a pesquisa no campo da Educação em geral, e especificamente no campo da Lingüística Aplicada ao Ensino de Língua Estrangeira, privilegiou o uso de experimentos controlados e métodos quantitativos de análise de dados. Essa tendência, claramente influenciada pelas ciências objetivas, teve como um de seus resultados mais aparentes o crescimento do abismo entre as 
conclusões das pesquisas e as práticas de sala de aula (OLSON, 1990). Para tentar minimizar essa situação, surgiu a Pesquisa em Sala de Aula que, na definição de ALLWRIGHT \& BAILEY (1991), é aquela que investiga o processo de ensino e aprendizagem no cenário da sala de aula, ou seja, tem como principal objeto de estudo aquilo que realmente acontece dentro da sala de aula.

Nos últimos anos, a pesquisa em sala de aula trilhou variados caminhos, porém, segundo FREEMAN (1996a), o professor somente começou a ocupar espaço nessas pesquisas no final dos anos 80 . Nessa época, vários autores já sugeriam a reflexão como caminho para o desenvolvimento do professor. Dentre eles, RICHARDS \& LOCKHART (1994) propuseram uma abordagem reflexiva para uma melhor compreensão do processo de ensino e aprendizagem de língua estrangeira e WALLACE (1991) sugere um modelo reflexivo para a formação do professor de LE que, além de levar em consideração as fontes de aprendizagem do professor, coloca a prática em sala de aula como um pré-requisito central para se chegar à competência profissional.

A partir dos anos 90, a pesquisa sobre o professor de LE se diversificou bastante. FREEMAN \& RICHARDS (1996, p. 1) argumentam que "para melhor entender o ensino de língua, é necessário saber mais sobre professores de língua: o que eles fazem, como eles pensam, e como eles aprendem."1

FREEMAN (1996b) discute a relação entre pesquisa e ensino, chamando atenção para sua natureza hierárquica e unidirecional. Para ele, dentro do campo do ensino de L2, há a pressuposição equivocada de que os resultados das pesquisas devem influenciar o ensino. Especificamente no campo das pesquisas sobre o conhecimento do professor, Freeman aponta para um dilema central: o eterno divórcio entre pesquisa e ensino, já que aqueles que conhecem a sala de aula a fundo (professores e alunos) raramente expõem esse conhecimento, ao passo que aqueles que se propõem a falar sobre a sala de aula (pesquisadores) não a conhecem a fundo (ibid., p. 90). Freeman propõe, então, que 
"para (...) entender o ensino completamente, precisamos adotar uma abordagem que coloque a pessoa que faz o serviço no centro. (...) $\mathrm{O}$ que os professores sabem, e como esse conhecimento se manifesta em sua prática, deve tornar-se uma preocupação vital daqueles que querem entender e influenciar a educação" (ibid., p.90).

$\mathrm{O}$ autor discute as pesquisas sobre o professor de LE que, segundo ele, podem ser agrupadas em três diferentes tendências, dependendo do ponto de vista assumido pelo pesquisador e da importância atribuída às contribuições do professor-pesquisado. Essas tendências foram denominadas Visão Comportamental, Visão Cognitiva e Visão Interpretativista ${ }^{2}$ e serão discutidas a seguir.

\section{A Visão Comportamental}

A primeira tendência inclui as pesquisas que abordam a participação do professor no processo de ensino/aprendizagem a partir de uma visão comportamental, ou seja, focalizam o comportamento do professor dentro da sala de aula. Nessa concepção, o ensino é visto como um meio de se transmitir conteúdos, e não como uma atividade em si mesma, e "é compreendido em termos dos resultados que produz" (FREEMAN, 1996a, p. 355). Freeman ressalta que essas pesquisas são orientadas para o produto e não para o processo de aprendizagem. São pesquisas que tratam o ensino como um conjunto de atividades padronizadas, tentando relacionar "o que os professores fazem durante as aulas, os processos que eles usam, com o que os alunos fazem, ou o que eles aprendem, como produtos dessas aulas" (1996b, p. 91). ${ }^{3}$

As conclusões dessas pesquisas se concretizam em termos de generalizações de padrões de atividades e comportamentos a partir das ações de professores e alunos dentro de uma sala de aula, porém os resultados são "divorciados tanto do mundo em que [o ensino] ocorre quanto da pessoa que o realiza" (ibid., p. 91). Como exemplo para esse tipo de pesquisa, temos as pesquisas realizadas sobre o tempo que o professor espera após ter lançado uma pergunta e antes que chame um aluno qualquer para respondê-la, um construto 
denominado "wait time". Segundo FREEMAN (ibid., p. 92-3), os pesquisadores tentavam estabelecer uma relação entre o tempo de espera do professor e a acuidade das respostas dos alunos.

A crítica que o autor faz a esse tipo de pesquisa recai no fato de que essa visão tenta codificar "processos extremamente complexos", simplificando o ato de ensinar justamente por desconsiderar o papel dos participantes (alunos e professores), enquanto seres pensantes. Os resultados dessas pesquisas promovem, assim, uma visão compartimentalizada do ensino, divorciada da pessoa do professor, e distanciada dos contextos em que ocorre (ibid., p. 93-4).

\section{A Visão Cognitiva}

Uma segunda tendência inclui as pesquisas que abordam o professor a partir de uma visão cognitiva, ou seja, focalizam os processos mentais do professor, suas percepções e intenções, suas crenças, seu raciocínio, seu conhecimento, suas atitudes e as dimensões afetivas (como ansiedade, insegurança, etc.) que inevitavelmente acompanham a sua prática diária, dando forma ao seu comportamento e às suas ações. Essa tendência encampa as pesquisas conhecidas como "teacher cognition" ou "teacher thinking" (FREEMAN \& RICHARDS, 1996) e constituem um avanço em relação à visão comportamental, assumindo uma perspectiva que combina pensamento e ação.

FREEMAN (1996b, p. 94) cita HALKES \& OLSEN (1984) para exemplificar o novo interesse dos pesquisadores dessa linha:

"A partir de uma perspectiva do pensamento do professor sobre ensino e aprendizagem, não se está mais à procura de $\boldsymbol{o}$ professor eficaz, mas da explicação e da compreensão dos processos de ensino como são.(...) Ao invés de reduzir as complexidades das situações de ensino e aprendizagem a algumas poucas variáveis de pesquisa manuseáveis, tenta-se descobrir como os professores lidam com essas complexidades." (HALKES \& OLSEN, 1984 apud FREEMAN, 1996b, p. 95 $)^{4}$ 
Esse tipo de pesquisa procura estudar, portanto, não apenas o que os professores fazem dentro da sala de aula, em termos de comportamento e ações, mas também o que eles pensam ao terem comportamentos ou realizarem ações específicas. Exemplos de pesquisas que assumem esse ponto de vista são encontrados nas pesquisas sobre planejamento de aulas, que utilizam a tomada de decisão ("decision making") como construto. ${ }^{5}$ WOODS (1996), por exemplo, examina como e o que os professores pensam em sua prática de ensino. A partir de um estudo de caso de oito professores de Inglês como L2 em quatro diferentes universidades no Canadá, o autor examina as práticas de planejamento dos professores envolvidos tanto durante a preparação de suas aulas quanto durante o processo de tomada de decisão no momento em que a aula acontece.

FREEMAN (1996b) ressalta que essas pesquisas tentam relacionar o que os professores pensam antes de dar uma aula ("pre-active decisions") com o que eles pensam ao dar essa aula ("interactive decisions"). Os resultados dessas pesquisas, segundo Freeman, mostram que os professores normalmente não planejam aulas em termos de objetivos de ensino mas sim em termos de atividades a serem desenvolvidas com determinados grupos de alunos em determinada situação. Freeman conclui, então, que "ensinar não é apenas uma atividade que liga pensamento e ação [mas] está geralmente enraizada de forma complexa num contexto particular" (ibid., p. 97).

\section{A Visão Interpretativista}

A terceira tendência, proposta por Freeman como alternativa, e ainda pouco explorada, inclui pesquisas que focalizam o professor a partir de uma visão interpretativista, isto é, o foco principal é a tentativa de compreender como os professores interpretam a sua própria prática em relação ao contexto específico em que estão atuando. Para o autor, "os professores estão constantemente envolvidos em interpretar seus mundos: eles interpretam o assunto que ensinam, o contexto de suas salas de aula, e as pessoas ali presentes" (ibid., 
p. 98). O contexto em que trabalham assume, portanto, uma importância central para o pensamento e as ações dos professores. Na opinião de Freeman, os professores se utilizam de um conhecimento altamente complexo e interpretativo para ensinar. Assim, para compreender o ensino é preciso entender "como os professores interpretam seus mundos" (ibid., p. 99).

Dessa forma, Freeman identifica o professor e a formação do professor como "o problema não estudado", principalmente no âmbito do ensino de línguas, "onde práticas tradicionais, sabedoria convencional, e conhecimento disciplinar têm sido dominantes" (1996a, p. 374). Freeman postula, portanto, que é preciso colocar no centro das pesquisas tanto as perspectivas quanto as vozes dos próprios professores. Um ponto de vista, que inclui não só as conclusões do pesquisador mas também a voz do professor-pesquisado (1996b, p. 100).

A partir desse novo ponto de vista, o papel da pesquisa passa a ser, então, encontrar interpretações viáveis para as percepções do professor. Questões cruciais para esse tipo de pesquisa seriam o que é ensino e o que é necessário saber para ensinar. São essas questões que, segundo o autor, devem ser abordadas por aqueles interessados na formação de professores.

Já dentro dessa nova linha de pesquisa, RICHARDS (1998) relata os resultados de uma pesquisa realizada durante um programa de mestrado para professores de L2, utilizando diários de ensino para fomentar a reflexão crítica dos participantes. Os pesquisadores solicitaram aos participantes que escrevessem seus diários de ensino regularmente e que, ao final de cada registro, fizessem duas ou três perguntas relacionadas ao conteúdo daquele registro. Os participantes, então, levavam seus diários para seus encontros tutoriais e lá compartilhavam suas reflexões, lendo os diários dos colegas e respondendo às perguntas propostas. Para a análise das reflexões feitas pelos participantes, os pesquisadores selecionaram 10 diários e identificaram e categorizaram os tópicos abordados. Essa categorização, apresentada abaixo, foi utilizada como ponto de partida para a análise dos dados da pesquisa aqui relatada. 


\section{RELAÇÃO DAS CATEGORIAS REFLEXIVAS (RICHARDS, 1998, p. 159)}

\section{Teorias de ensino}

Teorias e crenças sobre ensino e aprendizagem

- uma crença ou convicção (ex: o que é ser um bom professor)

- a visão de um especialista (ex: referir-se às idéias de Krashen sobre aquisição de L2)

- uma justificativa para algo (ex: descrever uma teoria para justificar algo que o professor fez)

- uma opinião pessoal (ex: expressar uma opinião sobre a importância da observação de aula)

Aplicação de teorias à prática de sala de aula

- como uma teoria foi aplicada (ex: experimentar uma estratégia de elicitação descrita numa palestra)

- contradições entre teoria e prática (ex: descrever por que um evento de sala de aula não sustenta uma teoria)

- como as teorias mudaram (ex: como as experiências de sala de aula mudaram as teorias do professor)

\section{Abordagens e métodos}

Abordagens e métodos de ensino

- uma abordagem ou um procedimento (ex: a abordagem do professor para o ensino de leitura ou os procedimentos usados durante uma tarefa de compreensão oral)

O conteúdo de uma lição (ex: a descrição do conteúdo de uma lição de gramática)

O conhecimento do professor

- conhecimento pedagógico (ex: conhecimento sobre as exigências das tarefas de classe)

- conhecimento e experiência (ex: mencionar como sua maneira de ensinar tornou-se mais centrada no aluno)

O conhecimento prévio do aluno (ex: mencionar que os alunos têm pouca oportunidade de praticar inglês fora da sala de aula) 
O contexto da escola

- a relação entre ensino e o contexto da escola (ex: como as exigências administrativas ou as políticas da escola afetam o ensino)

\section{Avaliações do ensino}

Avaliação de aulas

- avaliações positivas (ex: comentar que a aula foi bem porque todos os alunos participaram)

- avaliações negativas (ex: mencionar que a aula não atingiu seus objetivos)

Diagnóstico de problemas

- problemas dos alunos (ex: dificuldades que os alunos tiveram com determinados pontos gramaticais)

- interação de sala de aula (ex: comentar que uma atividade de grupo não funcionou porque os alunos tiveram problemas de interação em grupo)

- problemas do professor (ex: o professor não teve tempo para corrigir os deveres de casa dos alunos)

\section{Solução de problemas}

- formas alternativas de apresentar uma lição (ex: começar uma lição de forma diferente)

- decisão de adotar um plano de ação (ex: decidir usar atividades de "role play" com mais freqüência)

- pedir ajuda ao tutor (ex: perguntar como superar determinadas dificuldades)

\section{Auto-percepção}

Percepções de si mesmo como professor

- seu estilo de ensinar (ex: descrever o estilo de ensinar com o qual ele se sente mais à vontade, como por exemplo um estilo centrado no professor)

- comentários sobre sua proficiência na língua (ex: dizer que não fala inglês fluentemente) 


\section{Reconhecimento de crescimento pessoal}

- como a auto-confiança se desenvolveu (ex: mencionar que tem sido menos afetado por problemas de ensino do que antes)

\section{Estabelecer objetivos pessoais}

- auto-desenvolvimento (ex: identificar aspectos de sua maneira de ensinar para serem trabalhados no futuro)

\section{A PESQUISA}

Partindo, então, do modelo reflexivo de WALLACE (1991) e das sugestões de pesquisas interpretativistas de FREEMAN (1996b), esse estudo teve por objetivo buscar uma compreensão global sobre como o professor de inglês interpreta sua sala de aula. ${ }^{6}$ A informante da pesquisa foi uma professora de inglês do CENEX (Centro de Extensão) ${ }^{7}$ da FALE/UFMG, que estava terminando seu curso de licenciatura em inglês e não tinha experiência anterior de ensino.

A pesquisa utilizou entrevistas de retrospecção estimuladas por gravações em vídeo das aulas da professora-informante. Durante um mês, as aulas da informante foram gravadas em vídeo. Após cada gravação eram realizadas entrevistas de retrospecção, nas quais a informante, ao rever as imagens de suas aulas gravadas, forneceu suas interpretações sobre os eventos ocorridos. Essas entrevistas, num total de oito, foram gravadas e mais tarde transcritas. O conteúdo das transcrições foi, então, analisado tomando por base as categorias reflexivas propostas por RICHARDS (1998).

\section{OS RESULTADOS}

A análise revelou, porém, que a categorização proposta por Richards (ibid.) não era suficiente para representar a totalidade dos padrões encontrados nos dados coletados. Essa categorização foi, então, expandida para que melhor se acomodasse aos dados coletados. Assim, foram criadas novas categorias que não estavam presentes na proposta do autor, da mesma forma que uma das 
categorias propostas por ele foi excluída, pois não foram encontrados nos dados exemplos que nela se enquadrassem. Além disso, algumas categorias presentes na relação inicial foram modificadas para que melhor representassem os dados desta pesquisa. Desta forma, obteve-se a seguinte relação final de categorias reflexivas utilizadas para codificar os dados desta pesquisa:

\section{RELAÇÃO EXPANDIDA DE CATEGORIAS REFLEXIVAS}

\section{I - Teorias de ensino}

\section{1 - Teorias e crenças sobre ensino e aprendizagem}

- uma crença ou convicção (ex: o que é ser um bom professor)

- a visão de um especialista (ex: referir-se às idéias de seus professores na universidade)

- uma justificativa para algo (ex: descrever uma teoria ou crença para justificar algo que o professor fez)

- uma opinião pessoal (ex: expressar uma opinião sobre a importância da observação de aula)

\section{2 - Aplicação de teorias à prática de sala de aula}

- como uma teoria foi aplicada (ex: experimentar uma estratégia de elicitação descrita numa palestra)

- contradições entre teoria e prática (ex: descrever por que um evento de sala de aula não sustenta uma teoria)

- como as teorias mudaram (ex: como as experiências de sala de aula mudaram as teorias do professor)

\section{II - Abordagens e métodos}

\section{1 - Abordagens e métodos de ensino}

- uma abordagem ou um procedimento (ex: a abordagem do professor para o ensino de leitura ou os procedimentos usados durante uma tarefa de compreensão oral)

- justificativas para o uso de uma abordagem ou procedimento (ex: explicar por que usou determinado procedimento para apresentação ou prática de um conteúdo) 


\section{2 - Conteúdos de ensino}

- o conteúdo de uma lição ou atividade (ex: descrição do conteúdo de uma lição de gramática)

- o material didático (ex: comentários sobre um exercício proposto pelo livro didático)

\section{3 - O conhecimento do professor}

- conhecimento pedagógico (ex: conhecimento sobre as exigências das tarefas de classe)

- conhecimento e experiência (ex: mencionar como sua maneira de ensinar mudou)

\section{4 - O aluno}

- as informações prévias do aluno (ex: mencionar que os alunos têm pouca oportunidade de praticar inglês fora da sala de aula)

- percepções sobre o aluno (ex: mencionar que um aluno é tímido ou extrovertido)

\section{5 - O contexto}

- a relação entre ensino e contexto (ex: como os níveis anteriores afetam o ensino)

- as pressões à sala de aula (ex: mencionar fatores que influenciam a sala de aula)

\section{III - Avaliações do ensino}

\section{1 - Avaliação de aulas}

- avaliações positivas (ex: comentar que a aula foi bem porque todos os alunos participaram)

- avaliações negativas (ex: mencionar que a aula não atingiu seus objetivos)

\section{2 - Diagnóstico de problemas}

- problemas dos alunos (ex: dificuldades que os alunos tiveram com determinados pontos gramaticais)

- interação de sala de aula (ex: comentar que uma atividade de grupo não funcionou porque os alunos tiveram problemas de interação em grupo)

- problemas do professor (ex: o professor não teve tempo para preparar uma tarefa extra) 


\section{3 - Solução de problemas}

- formas alternativas de apresentar uma lição (ex: começar uma lição de forma diferente)

- decisão de adotar um plano de ação (ex: decidir usar "pair work" com mais freqüência)

- formas de buscar ajuda (ex: pedir ajuda a professores e colegas ou buscar ajuda em dicionários e gramáticas)

\section{IV - Auto-percepção}

\section{1 - Percepções de si mesmo como professor}

- seu estilo de ensinar (ex: descrever o estilo de ensinar com o qual ele mais se identifica)

- seu estilo de aprender (ex: comentar sobre sua maneira preferencial de aprender)

- comentários sobre sua proficiência na língua (ex: dizer que não fala inglês fluentemente)

\section{2 - Reconhecimento de crescimento pessoal}

- como a pesquisa ajudou (ex: mencionar que o uso do vídeo ajuda a perceber problemas)

\section{3 - Estabelecer objetivos pessoais}

- auto-desenvolvimento (ex: identificar aspectos de sua maneira de ensinar que devem ser trabalhados)

- planos para o futuro (ex: mencionar que deseja melhorar seu comando da língua estrangeira)

Como se vê, a relação final de categorias reflexivas apresenta quatro grandes conjuntos de categorias: Teorias de Ensino; Abordagens e Métodos; Avaliações do Ensino; Auto-percepção. Cada um desses conjuntos foi dividido em dois ou mais subconjuntos, os quais contêm pelo menos uma categoria reflexiva cada.

No total, a relação expandida de categorias reflexivas contém trinta e uma categorias diferentes. As novas categorias e aquelas que receberam modificações estão representadas em itálico para facilitar sua visualização. Além das alterações feitas nas categorias 
propriamente ditas, vários dos exemplos originalmente citados por RICHARDS (1998) foram modificados, para que melhor representassem os exemplos encontrados nos dados.

A seguir será apresentada uma descrição de cada uma dessas categorias, juntamente com exemplos ${ }^{8}$ encontrados nos dados para cada uma delas. Em cada exemplo, o trecho específico que se refere à categoria em questão foi colocado em itálico.

\section{I - Teorias de ensino}

\section{1 - Teorias e crenças sobre ensino e aprendizagem}

- Uma crença ou convicção: nesta categoria foram incluídos os trechos das entrevistas de retrospecção onde a informante se referiu às suas crenças e convicções sobre assuntos relacionados ao ensino e à aprendizagem de LE. Essas poderiam ser tanto crenças e convicções pessoais quanto aquelas amplamente difundidas e aceitas na área da Lingüística Aplicada ao ensino de língua estrangeira.

Exemplo:

I - "Aquele exercício lá do vocabulário, dos verbos de comida, de cozinhar ...

[Outros comentários não-relevantes para esta categoria]

I - "Ways of Cooking". É. Aí, não ia ter muito a ver com o que a gente já estava falando, a lição era sobre quantidade, né, "quantifiers", "countability", e aí eu não quis ficar aumentando mais ... porque, pra dar vocabulário assim é muito ... não pode só ir jogando assim ...

$\mathbf{P}$ - Perdido assim, né.

I - É, tem que ter contexto. (...)"

Segunda entrevista - p. 12 (discussão da aula gravada em 06/ 05/99)

- A visão de um especialista: nesta categoria foram incluídos os trechos em que a informante referiu-se a pessoas consideradas especialistas na área de ensino/aprendizagem de LE. Especificamente, esses trechos representam momentos em que a informante citou idéias e técnicas aprendidas com seus professores universitários, durante o seu curso de Letras, ou com os supervisores do CENEX, durante reuniões e cursos de treinamento. 


\section{Exemplo:}

P - "Bom, primeiro eu queria te perguntar sobre esses símbolos de correção de redação. Como você ficou conhecendo isso, onde você aprendeu?... você já passou por essa experiência de alguém corrigir seus trabalhos assim ?...

I - Já. Eu conheci esse processo, essa maneira de corrigir o writing com ... duas professoras minhas... uma de lingua inglesa, que ela corrigia o writing assim, e na disciplina de produção de textos. E, ... aí eu acho que é o melhor, ainda mais pra esse tipo de aluno, que quer ter um conhecimento da língua mas ... não precisa ser muito detalhado. Então, eu acho que isso ajuda muito (...)"

Terceira entrevista - p. 1 (discussão da aula gravada em 11/05/99)

- Uma justificativa para algo: os trechos incluídos nesta categoria representam os momentos em que a informante justificou sua atuação dentro da sala de aula com base em alguma teoria de ensino/ aprendizagem de LE ou com base em alguma crença ou convicção pessoal.

Exemplo:

I - "Eu não sou muito a favor de mandar aluno ler em sala, não. Porque ... tem o lado bom, você fazer ele ler, ele treina, de alguma maneira pode ajudar, mas ... eu acho que ... quando você está lendo você não presta muita atenção, igual se você estivesse lendo em voz baixa, ou se uma pessoa estivesse lendo e você estivesse só seguindo a leitura. Então, eu não gosto muito de mandar aluno ler em sala, não. Se eu mandar ler, mando ler em silêncio. Não gosto de ficar mandando ler alto, não. Só se quiser."

Terceira entrevista - p. 9 (discussão da aula gravada em 11/05/99)

- Uma opinião pessoal: nesta categoria foram incluídos os trechos em que a informante expressou sua opinião sobre assuntos variados, como a importância da observação de aula, a dificuldade de encontrar certos materiais didáticos de apoio, a precariedade do sistema de ensino brasileiro ou qualquer outro julgamento de valor feito sobre questões de ensino e aprendizagem de LE durante as entrevistas. 
Exemplo:

$\mathbf{P}$ - "Agora, as questões de verdadeiro e falso que você elaborou sobre o vídeo ... tem alguma que tenha a ver com a matéria que você estava dando no livro?

I - Não, não. É compreensão mesmo, né, "listening comprehension", então, assim, eu acho que se tiver alguma coisa a ver com o que elas estão vendo, legal, mas não é fácil você achar uma coisa que seja interessante e que abrange o que elas estão vendo. Então, acho que não. Eu não me preocupei de ser alguma coisa que elas estavam vendo, não."

Quinta entrevista - p. 6 (discussão da aula gravada em 18/05/99)

\section{2 - Aplicação de teorias à prática de sala de aula}

- Como uma teoria foi aplicada: nesta categoria foram incluídos todos os trechos em que a informante descreveu a maneira como ela aplicou uma teoria ou sugestão de um especialista em sua sala de aula. Essa teoria ou sugestão pode ter sido aprendida num livro, numa palestra ou num curso de treinamento. Pode, também, ter sido experienciada pela própria informante durante seu curso de graduação ou em outros cursos anteriores.

Exemplo:

I - "Eu procuro usar [o quadro], né, dessa maneira ... Porque ... geralmente, quando eu estou usando mais o quadro, igual no caso do 'ing', eu uso ali a maior parte do quadro ... mas eu deixo sempre lá o canto, assim, eu vou colocando o vocabulário que elas têm dúvidas, ou alguma palavra que elas pedem ...como éque escreve ... e outros vocabulários, eu escrevo lá, ... eu deixo o canto para isso ... porque aípode deixar lá, e elas vão vendo as palauras novas ... e fica mais organizado, eu não preciso ficar escrevendo e apagando, eu deixo lá. (pausa) E isso eu peguei de uma professora minha de espanhol. Isso eu achava interessante, ela deixar, assim, um lugarzinho lá pro ... vocabulário."

Primeira entrevista - p. 10 (discussão da aula gravada em 04/05/99)

- Contradições entre teoria e prática: esta categoria inclui os trechos representativos dos momentos em que a informante identificou algum tipo de contradição entre as teorias de ensino/aprendizagem que ela conhece e a aplicação prática dessas teorias. 
Exemplo:

I - "Os alunos, eu já falei que tem uns que tem mais facilidade, tem uns que falam mesmo - acho que toda classe vai ter isso. (...) Mas, aí tem também o lado do professor, do ... "teaching time", que é você deixar o aluno falar mais, e fazer perguntas, e ter uma atitude em que você faça com que os alunos falem mais, em que você fale o menos possivel, pra ele poder falar. Mas acho que ... eu ainda não consigo ver ... uma aula que o aluno fale mais do que o professor."

Terceira entrevista - p. 12-3 (discussão da aula gravada em 11/05/99)

- Como as teorias mudaram: os trechos incluídos nesta categoria representam momentos em que a informante se refere a mudanças em suas teorias, crenças e convicções devido a experiências vividas dentro de sua sala de aula.

Exemplo:

I - "Aí eu acho que a tradução é pra ajudar elas a entenderem, né, porque foi esse ponto na lição que deu problema, de eu esclarecer direito pra elas. (...) E eu vi que a tradução era ...é viável, totalmente útil nessa hora, pra você poder comparar, né. Então, aí eu quis de novo fazer essa tradução pra garantir isso, (risos) ver se elas tinham entendido mesmo. Eu acho que dá certo a tradução nessa hora, assim, eu acho que é importante." Sétima entrevista - p. 7 (discussão da aula gravada em 25/05/99)

\section{II - Abordagens e métodos}

\section{1 - Abordagens e métodos de ensino}

- Uma abordagem ou um procedimento: nesta categoria foram incluídos os trechos em que a informante descreveu uma abordagem utilizada para ensinar determinado conteúdo didático ou os procedimentos usados durante uma tarefa ou atividade.

Exemplo:

I - "(...) Porque ... é por causa da pronúncia. Em vez de eu falar "não, não é assim, é assim", ai eu vou e repito a frase certa.

$\mathbf{P}$ - E você acha que elas notam? 
I - Notam, eu acho que elas notam. E ... mas se for alguma coisa específica, se for uma palavra muito complicada, ai eu chamo atenção pra aquela palavra."

Primeira entrevista - p. 19 (discussão da aula gravada em 04/05/99)

- Justificativas para o uso de uma abordagem ou procedimento: esta categoria inclui os trechos em que a informante justifica o uso de uma abordagem ou procedimento de ensino. Os trechos aqui incluídos diferem dos trechos incluídos na categoria "uma justificativa para algo", descrita acima, porque aqui as justificativas usadas pela informante não são baseadas em teorias, crenças, convicções ou opiniões pessoais.

Exemplo:

$\mathbf{P}$ - "Essa atividade, você começou lendo as idéias que eles estavam sugerindo pra ajudar o ambiente, a ecologia, ... e aí, no início você estava perguntando se elas concordam, se não concordam, o que elas fazem na casa delas, etc. Depois, do terceiro em diante eu achei que você não perguntou mais se elas concordavam ou não. O que aconteceu?

I- Ah, é que eu acho que aí elas tiveram muita dúvida de vocabulário. Acho que as dúvidas de vocabulário acabaram ... desviou o foco da atividade que era pra falar só do 'agree or don't agree' ..."

Terceira entrevista - p. 7 (discussão da aula gravada em 11/05/99)

\section{2 - Conteúdos de ensino}

- O conteúdo de uma lição ou atividade: nesta categoria foram incluídos os trechos em que a informante descreveu o conteúdo de uma lição ou de uma atividade.

Exemplo:

I - "Nessa hora ... a gente estava continuando a lição sobre ... aparências, adjetivos para aparência física, pra descreverpessoas ... eu já tinha terminado com isso na aula passada, e essa aula eu estava continuando pra ... quer dizer, na aula passada foi só mais pra pegar a estrutura, como é que fala o verbo, a diferença do 'look-look like', e agora essa foi mais pra pegar os adjetivos, pra eles aprenderem esses adjetivos para descrever as pessoas." Primeira entrevista - p. 3 (discussão da aula gravada em 04/05/99) 
- O material didático: esta categoria inclui os trechos em que a informante teceu comentários sobre as características do livro didático ou de atividades e exercícios nele propostos.

Exemplo:

I - "Esse 'grammar file' no livro ... O livro sugere, assim: 'gasta tantos minutos, só faz a leitura'. Aípronto, vê se tem dúvida. Mas eu acho que é muito chato, assim, ficar só lendo, lendo. Porque já é uma coisa chata ficar falando de gramática, regra, e esses detalhes todos. Aí, só ler e pronto, acabou, eu acho muito mais... (...) Mas esse livro, ele é comunicativo, mas ... Esse negócio de comunicativo, isso é complicado ... nem sei o que é comunicativo."

Sétima entrevista - p. 6 (discussão da aula gravada em 25/05/99)

\section{3 - O conhecimento do professor}

- Conhecimento pedagógico: os trechos incluídos nesta categoria representam momentos em que a informante revelou seus conhecimentos pedagógicos, ou seja, aqueles relacionados às tarefas e atividades pedagógicas.

Exemplo:

I- "Eu acho que ... com pouca [gente na] turma ... tem o lado positivo ... tem o lado bom de você conhecer, você pode dar mais atenção pra cada um individualmente. (...) Eles [os alunos] têm mais como trabalhar, trocam informação, mas ... agora ... quando [o aluno] falta, aí o lado ruim é isso, quando falta, fica muito pouca gente, e fica ruim, assim ... parece que você não pode fazer muita coisa, o ritmo cai, e você não pode avançar muito."

Quarta entrevista - p. 1 (discussão da aula gravada em 13/05/99)

- Conhecimento e experiência: nesta categoria foram incluídos os trechos onde a informante revelou conhecimentos advindos da sua experiência como professora, isto é, aqueles conhecimentos que ela adquiriu a partir de sua própria prática de sala de aula. 


\section{Exemplo:}

I - "Começando esse exercício aí, esse 'taking things back', eu me lembrei de uma coisa. Que de umas aulas pra cá, eu tenbo mostrado mais no livro, em vez de ir só lendo, falar assim 'número tal', e aí 'é pra fazer isso' ... ai eu passei a mostrar mais, assim, no livro, 'isso aqui, e tal' [apontando para o livro], porque ... sempre eu via que a MF ficava muito perdida ... ela tem mais dificuldade de pegar as coisas. Então, eu achei que mostrando assim ia ser mais fácil pra elas seguirem, pra elas se acharem. Eu percebi isso observando mesmo, na hora que eu começava uma coisa, eu via que sempre a MF custava a ver onde que era, ou ia e perguntava a outra do lado e ..."

Sexta entrevista - p. 5-6 (discussão da aula gravada em 20/05/99)

\section{4 - O aluno}

- As informações prévias do aluno: nesta categoria encontram-se os trechos em que a informante demonstrou estar ciente do conhecimento anterior e das informações prévias de suas alunas, como aquilo a que elas tinham acesso fora da sala de aula ou os pontos gramaticais que elas estavam vendo pela primeira vez.

\section{Exemplos:}

I - "Eu acho que ... elas tiveram dúvidas, mas eu acho que foi normal, porque era o que elas estavam vendo de novo [pela primeira vez], que era esse 'phrasal verb', o 'try on'."

Quinta entrevista - p. 3 (discussão da aula gravada em 27/05/99)

- Percepções sobre o aluno: nesta categoria foram incluídos os trechos em que a informante se refere às características pessoais de suas alunas, como timidez, auto-confiança ou dificuldades com a língua.

Exemplo:

I - “(...) ... éporque elas [as alunas] já têm dificuldade, (...) porque elas não são de falar... Porque a ML, ela já é falante, ela já conversa com todo mundo, já fala mesmo, naturalmente, já é personalidade dela. As duas [J e MF] já são mais tímidas... e ainda têm mais dificuldade com a lingua."

Sexta entrevista - p. 6 (discussão da aula gravada em 20/05/99) 


\section{5 - O Contexto}

- A relação entre ensino e contexto: nesta categoria foram incluídos trechos em que a informante relata como os níveis anteriores influenciam positiva ou negativamente a sala de aula.

Exemplo:

I - “... É... elas não participam muito, né... Aí eu acho que o negócio é o nível... porque já é o $4^{\circ}$. estágio, mas às vezes os três primeiros estágios também... não sei, às vezes por causa do tempo ... o professor, nos outros estágios, não exige, né, não orienta mais a fala toda, completa, não faz repetir ... ou não faz eles [os alunos] verem como é a fala certa ... Acho que às vezes isso também pode atrapalhar o nível deles."

Terceira entrevista - p. 12 (discussão da aula gravada em 11/05/99)

- As pressões à sala de aula: nesta categoria foram incluídos os trechos em que a informante se refere à pressões, sejam elas internas ou externas, sofridas dentro da sala de aula.

Exemplo:

I - “(...) Então, e eu esqueci de fazer essas perguntas, de fazer essa discussão.

$\mathbf{P}$ - Então foi por causa de ansiedade. Ansiedade por quê?

I - Por causa do tempo. Essa turma é muito ... o tempo sempre é curto pra tudo que eu planejo. (risos) Então, ... nem pensei no Grammar Focus, já fui passando pra frente, e ... deixei isso pra trás."

Primeira entrevista - p. 19 (discussão da aula gravada em 04/05/99)

\section{III - Avaliações do ensino}

\section{1 - Avaliação de aulas}

- Avaliações positivas: os trechos incluídos nesta categoria representam as ocasiões em que a informante teceu comentários positivos sobre suas aulas ou sobre os eventos nela ocorridos.

Exemplo:

I - "Ah, eu já tinha pensado que eu ia falar de um filme. Eu já tinha pensado que eu ia dar um exemplo, assim, de um filme, mas 
não estava muito claro que era o 'Titanic'. Aí, na hora que eu lembrei, ... eu sei que elas tinham assistido. Porque é um filme que todo mundo sabe. Então, eu achei que seria bom usar ele (risos). Efoi bom que tinha gente que já tinha assistido e gente que não tinha assistido. Então ... foi bom por isso, porque teve uma que não tinha assistido, ai foi melhor ainda."

Sétima entrevista - p. 11 (discussão da aula gravada em 25/05/99)

- Avaliações negativas: esta categoria inclui os trechos em que a informante teceu comentários negativos sobre suas aulas ou sobre os eventos nela ocorridos.

Exemplo:

I - "É ... esse texto ... essa introdução faltou ser ... trabalhada um pouco mais. Eu acho que eu fiquei muito restrita, só perguntei a elas isso, mas eu podia ter envolvido elas mais com esse título, [podia ter perguntado] por que os pássaros morreram e ... e, não sei, pra ver se elas ficavam mais interessadas, pra ver se o texto parecia mais interessante. Eu acho que faltou um pouco isso, no 'pre-reading'. (...) Eu ... acho que eu tinha que terpreparado melhor esse 'pre-reading'." Sétima entrevista - p. 11 (discussão da aula gravada em 25/05/99)

\section{2 - Diagnóstico de problemas}

- Problemas dos alunos: nesta categoria foram incluídos os trechos onde a informante se refere a dificuldades que suas alunas tiveram com determinados conteúdos didáticos ou problemas por elas enfrentados ao realizarem alguma tarefa.

Exemplo:

P - "Você achou que elas tiveram muita dificuldade nesse ponto [substantivos contáveis e incontáveis]?

I - Ab, achei. Eu achei muito complicado. Mas, aí, acho que tem o lado ... de já ter esse ponto da gente não ter isso aqui na língua [portuguesa] e elas quererem comparar, e também o método, o jeito que eu dei. Não sei, eu acho que ficou meio complicado, elas tiveram dificuldade."

Quarta entrevista - p. 3 (discussão da aula gravada em 13/05/99)

- Interação de sala de aula: esta categoria inclui os trechos em que a informante menciona dificuldades que suas alunas tiveram devido a problemas relacionados à interação entre elas ou com a professora. 
Exemplo:

I - "Essa palavra, eu acho que elas ficaram com mais dúvida. Porque elas não estavam conseguindo associar o que era o 'cap', porque que é 'snowcapped'. E eu ... acho que eu demorei a ... porque eu expliquei o 'cap', e tal, mas aí, eu não fiz a associação direito pra elas. Eu falei que 'cover the head', então 'cover the volcano... with snow'. E eu acho que ... por isso que elas demoraram a perceber mais, porque eu custei a explicar ... demorou mais pra explicar, a associar, pra elas pra ficar mais fácil."

Quarta entrevista - p. 11 (discussão da aula gravada em 13/05/99)

- Problemas do professor: os trechos incluídos nesta categoria se referem aos problemas relacionados à pessoa da informante que trouxeram conseqüências para a sala de aula, como momentos em que ela tem dificuldades para pensar em exemplos, situações em que ela deixou de realizar alguma idéia planejada anteriormente ou enganos na correção de tarefas das alunas.

Exemplo:

P - "Ali você estava comentando um item [do 'listening comprehension'] sobre a questão das cadeiras, porque [a personagem] sentou na mesa e tinha mais cadeiras em volta. Foi esse item que você falou que corrigiu errado?

I - Foi. Porque era 'he doesn't care ... ' - ele não se importava de ela sentar na mesa. E na verdade ele se importou. Então, era pra ser falso, porque ele 'cares'. Aí, elas colocaram verdadeiro $e$ eu, na hora de eu corrigir, eu me enganei. Foi falta de atenção... Sorte que a $\mathrm{V}$, que foi a única que tinha acertado (risos), então era a única que eu tinha marcado errado, né, aí ela veio me questionar. Aí eu consertei pra ela e tive que consertar das outras."

Sétima entrevista - p. 1 (discussão da aula gravada em 25/05/99)

\section{3 - Solução de problemas}

- Formas alternativas de apresentar uma lição: nesta categoria foram incluídos todos os trechos em que a informante se referiu a maneiras alternativas para apresentar ou desenvolver uma atividade ou tarefa discutida durante as entrevistas de retrospecção. 


\section{Exemplo:}

I - "Essa coisa aí do 'enough' e do 'too', eu acho que ... se ... logo ali no começo, eu já tivesse falado, colocado "enough = sufficient, necessary' e 'too = more than necessary' ... acho que desde o começo eu já devia ter colocado pra ficar mais claro pra elas. Eu acho que aí poderia ser mais claro, porque não ficou muito claro, não. (...) inclusive, atépra outra turma eu já vou fazer assim, pra ver se vai dar."

Quarta entrevista - p. 13 (discussão da aula gravada em 13/05/99)

- Decisão de adotar um plano de ação: nesta categoria foram incluídos os trechos onde a informante mencionou suas decisões tomadas a partir das reflexões realizadas durante as entrevistas ou a partir da sua própria experiência.

Exemplo:

I - "Ah! Por que todas sentam sempre no mesmo lugar? Eu não sei, não. Isso aí, desde a primeira aula que foi daquele jeito. (...) Mas eu ... já até pensei isso, em casa, que eu vou, agora quando tiver trabalho em par, em grupo, vou mandar elas trocarem um pouco, porque ficar só com a mesma aluna fica ... tem que mudar pra também ver as outras ... né, as conversas diferentes, então, ajuda."

Primeira Entrevista - p. 13 (discussão da aula gravada em 04/05/99)

- Formas de buscar ajuda: os trechos incluídos nesta categoria representam as diferentes formas que a informante utiliza para buscar ajuda nas situações que ela não consegue solucionar sozinha. Essas situações tanto podem estar relacionadas a problemas com alunos quanto a dificuldades pessoais com a língua ou com atividades de ensino.

\section{Exemplo:}

P - "Então você está falando que esse vocabulário você é que quis dar pra elas?

I- É.

$\mathbf{P}$ - E você foi buscar essa informação em algum lugar ou você já sabia isso?

I - Não, algumas eu já sabia e, peguei no dicionário, no Longman, que tem, né, 'describing people', tem um desenho de um tanto 
de gente, só de descrever pessoas, tinha até esses estilos de cabelo (risos)."

Primeira entrevista - p. 4 (discussão da aula gravada em 04/05/99)

\section{IV - Auto-percepção}

\section{1 - Percepções de si mesmo como professor}

- Seu estilo de ensinar: nesta categoria foram incluídos os trechos em que a informante se referiu à sua maneira preferida de ensinar uma habilidade ou às técnicas e abordagens com as quais mais se identifica.

Exemplo:

I - "(..) Mas agora pelo que eu estou vendo eu sou meio devagar (...) mas por causa disso. Porque eu também não gosto de ficar ... apressando o aluno e ... passar por cima das coisas por causa de tempo (...) Então, isso eu não gosto."

Primeira entrevista - p. 5 (discussão da aula gravada em 04/05/99)

- Seu estilo de aprender: esta categoria inclui os trechos em que a informante se referiu ao seu estilo preferido de aprender, seja no curso de graduação, seja em outras experiências de aprendizagem passadas.

Exemplo:

I - "Como aluna, desde que eu comecei a estudar inglês, eu nunca fui de fazer, assim, caderninho, fazer uma coisa pra juntar vocabulário, ou mesmo ficar estudando vocabulário. Mas por isso também que eu ainda sou meio deficiente nessa parte, né, tenho que reconhecer."

Oitava entrevista - p. 4 (discussão da aula gravada em 27/05/99)

- Comentários sobre sua proficiência na língua: nesta categoria foram incluídos os trechos onde a informante teceu comentários sobre suas dificuldades com a língua inglesa.

Exemplos:

$\mathbf{P}$ - "O que você acha que é mais difícil para um professor nãonativo? 
I - Eu ... acho que ... a língua, porque, às vezes, pra você explicar uma coisa, você ter que ficar só falando no Inglês ... falta alguma coisa, assim, porque você não é nativo, você não tem a fluência, assim, ou não fala muito bem, né, quase igual o nativo. Então fica meio difícil pra se expressar, às vezes ... pelo menos pra mim, é a minha dificuldade, né, com a lingua ..."

Quarta entrevista - p. 3 (discussão da aula gravada em 13/05/99)

\section{2 - Reconhecimento de crescimento pessoal}

- Como a pesquisa ajudou: nesta categoria foram incluídos os trechos onde a informante mencionou a importância da sua participação nesta pesquisa para o seu desenvolvimento profissional.

Exemplo:

$\mathbf{P}$ - "É ... eu acho que por hoje é só. O que você achou da experiência?

I - Eu gostei. Gostei muito. Eu achei, nossa, super produtivo pra mim, super ... está me ajudando demais, está ótimo, muito legal mesmo."

Primeira entrevista - p. 23 (discussão da aula gravada em 04/05/99)

\section{3 - Estabelecer objetivos pessoais}

- Auto-desenvolvimento: nos trechos incluídos nesta categoria, a informante identifica aspectos de sua maneira de ensinar que precisam ser trabalhados e desenvolvidos.

Exemplo:

$\mathbf{P}$ - "Onde você acha que esse tempo está escapando da sua mão?

I - É ... eu deixo tempo pra elas falarem, então ... vai ficando (...) elas têm o tempo delas, lá, que elas fazem ... Aí eu tento ... acelerar ou ... mas a maioria das vezes não consigo (risos) porque ... eu fico muito ... deixando o ritmo delas, como que elas estão fazendo, então, vou deixando ... tempo pra elas pensar, falar, e tal ... então, acho que eu tenho que saber mais administrar isso."

Primeira entrevista - p. 21 (discussão da aula gravada em 04/05/99)

- Planos para o futuro: os trechos incluídos nesta categoria representam os momentos em que a informante referiu-se a seus planos para o 
futuro, como sua vontade de estudar outras línguas estrangeiras e o desejo de melhorar seu comando da língua inglesa.

Exemplo:

P - "Mas isso acontece com qualquer pessoa [não-nativo]. Mas você vê isso como uma coisa muito ruim?

I - Não, mas eu gostaria de melhorar. Eu acho que seria melhor se eu tivesse uma fluência melhor, se eu não cometesse tantos erros assim, né?"

Primeira entrevista - p. 8 (discussão da aula gravada em 04/05/99)

Obteve-se, assim, uma visão global das percepções da informante sobre a sua sala de aula com base na categorização dos dados das entrevistas. No total foram analisados 582 trechos da fala da informante, a partir das transcrições das entrevistas de retrospecção. Após a categorização, esses trechos foram contados, ou seja, quantificados com o objetivo de se verificar quantos deles foram codificados em cada categoria. O ANEXO apresenta uma tabela contendo os resultados gerais dessa quantificação, que fornece um mapa global das percepções da informante sobre sua sala de aula.

\section{CONCLUSÃO}

Como foi visto, segundo FREEMAN (1996b), grande parte das pesquisas realizadas sobre o professor de LE ainda se limitam a apresentar as conclusões do pesquisador acerca do contexto estudado, revelando, por isso mesmo, uma visão compartimentalizada do processo de ensinar uma LE. Na opinião do autor, para melhor compreender a sala de aula de LE e os processos de ensino e aprendizagem que ali se desenvolvem, é preciso colocar a voz dos participantes no centro das pesquisas sobre o assunto. Para que se desenvolva um melhor entendimento sobre o que é ensinar, portanto, é necessário que se dê voz ao professor. A pesquisa aqui relatada tentou, através da retrospecção e da reflexão, permitir à informante expor suas percepções sobre os eventos ocorridos em sua sala de aula. Dessa forma, foi possível obter uma visão interpre- 
tativista, êmica e global da sala de aula da informante. Em primeiro lugar, obteve-se esta visão interpretativista porque a informante pôde, através da retrospecção, interpretar os acontecimentos ocorridos em sua sala de aula e tecer conclusões a respeito deles. Essas conclusões, por sua vez, delinearam um quadro por natureza êmico a respeito do contexto estudado, já que foram formuladas pela própria informante, na qualidade de participante direta do processo, e não por um observador externo. Por fim, a relação final de categorias reflexivas procurou fornecer um panorama geral das reflexões e interpretações da informante, revelando uma visão global e contextualizada do objeto estudado. Espera-se, assim, que os resultados obtidos possam contribuir para uma melhor compreensão da sala de aula de LE e dos processos de ensino ocorridos nesse contexto específico.

\section{NOTAS}

${ }^{1}$ Tradução minha, assim como todas as outras citações feitas a partir de autores estrangeiros, no restante deste trabalho.

${ }^{2}$ Tradução minha da seguinte terminologia usada pelo autor: "the behavioral view", "the cognitive view" e "the interpretivist view".

${ }^{3}$ Grifo do autor.

${ }^{4}$ Grifo do autor.

${ }^{5}$ Segundo FREEMAN (1996a), tomada de decisão foi o primeiro grande arcabouço teórico que permitiu examinar os processos mentais do professor.

${ }^{6}$ Os dados dessa pesquisa foram coletados em MATTOS (2000).

${ }^{7}$ O CENEX oferece cursos de línguas estrangeiras para alunos, professores e funcionários da UFMG e para a comunidade em geral. Os professores desses cursos são, preferencialmente, os alunos dos cursos de Letras da FALE (Faculdade de Letras), que ali cumprem seu estágio curricular.

${ }^{8}$ Convenções utilizadas na transcrição:

$\mathrm{I} \rightarrow$ Informante

$\mathrm{P} \rightarrow$ Pesquisadora 
$\ldots \rightarrow$ Pausa breve ou hesitação

[pausa] $\rightarrow$ Pausa longa

[ ] $\rightarrow$ Comentários da pesquisadora para facilitar a compreensão

$(\ldots) \rightarrow$ Comentários não-relevantes para o ponto em questão

$\mathrm{J}, \mathrm{MF}, \mathrm{ML}, \mathrm{V} \rightarrow$ Alunas do curso

\section{REFERÊNCIAS BIBLIOGRÁFICAS}

ALLWRIGHT, D.; BAILEY, K. Focus on the language classroom. New York: Cambridge University Press, 1991.

FREEMAN, D. The "unstudied problem": research on teacher learning in language teaching. In: FREEMAN, D.; RICHARDS, J. (Ed.) Teacher learning in language teaching. New York: Cambridge University Press, 1996a.

. Redefining the relationship between research and what teachers know.

In: BAILEY, K.; NUNAN, D. Voices from the language classroom. New York: Cambridge University Press, 1996b.

FREEMAN, D.; RICHARDS, J. (Ed.) Teacher learning in language teaching. New York: Cambridge University Press, 1996.

HALKES, R.; OLSEN, J. Teacher thinking: a new perspective on persisting problems in education. Lisse, Netherlands: Swets and Zeitlinger, 1984.

MATTOS, A. M. A. Percepções de uma professora de inglês sobre sua sala de aula: uma visão êmica. 2000. Dissertação (Mestrado em Estudos Lingüísticos) Faculdade de Letras, Universidade Federal de Minas Gerais, Belo Horizonte.

OLSON, M. W. (Ed.). The teacher as researcher: a historical perspective. In: OLSON, M. W. (Ed.). Opening the door to classroom research. Newark, Delaware: International Reading Association, 1990.

RICHARDS, J. C. Beyond training. New York: Cambridge University Press, 1998.

RICHARDS, J. C.; LOCKHART, C. Reflective teaching in second language classrooms. New York: Cambridge University Press, 1994.

WALLACE, M. J. Training foreign language teachers: a reflective approach. Glasgow: Cambridge University Press, 1991.

WOODS, D. Teacher cognition in language teaching: beliefs, decision-making and classroom practice. Cambridge: Cambridge University Press, 1996. 


\section{ANEXO}

Tabela de totalização dos trechos analisados

\begin{tabular}{|c|c|c|c|}
\hline \multicolumn{3}{|r|}{ Categorias } & \multirow{2}{*}{$\begin{array}{c}\text { Total } \\
58 \\
\end{array}$} \\
\hline \multirow{7}{*}{ 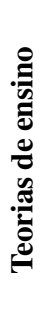 } & \multirow{4}{*}{$\begin{array}{c}\text { Teorias } \\
\mathrm{e} \\
\text { crenças }\end{array}$} & Crença ou convicção & \\
\hline & & Visão de um especialista & 10 \\
\hline & & Justificativa para algo & 27 \\
\hline & & Opinião pessoal & 20 \\
\hline & \multirow{3}{*}{$\begin{array}{l}\text { Aplicação } \\
\text { de teorias } \\
\text { à prática }\end{array}$} & Como uma teoria foi aplicada & 07 \\
\hline & & Contradições entre teoria e prática & 07 \\
\hline & & Como as teorias mudaram & 06 \\
\hline \multirow{10}{*}{ 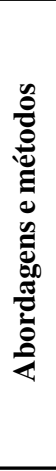 } & \multirow{2}{*}{$\begin{array}{l}\text { Abordagens } \\
\text { e métodos }\end{array}$} & Abordagem ou procedimento & 11 \\
\hline & & Justificativas ao uso de abordagens & 43 \\
\hline & \multirow{2}{*}{$\begin{array}{l}\text { Conteúdos } \\
\text { de ensino }\end{array}$} & Conteúdo de uma lição & 16 \\
\hline & & Material didático & 21 \\
\hline & \multirow{2}{*}{$\begin{array}{c}\text { Conhecimento } \\
\text { do professor }\end{array}$} & Conhecimento pedagógico & 18 \\
\hline & & Conhecimento e experiência & 09 \\
\hline & \multirow[t]{2}{*}{$\mathrm{O}$ aluno } & Informações prévias do aluno & 15 \\
\hline & & Percepções sobre o aluno & 38 \\
\hline & \multirow[t]{2}{*}{ Contexto } & Relação entre ensino e contexto & 06 \\
\hline & & Pressões à sala de aula & 57 \\
\hline \multirow{8}{*}{ 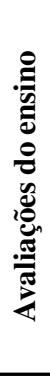 } & \multirow{2}{*}{$\begin{array}{c}\text { Avaliações } \\
\text { de aulas }\end{array}$} & Avaliações positivas & 25 \\
\hline & & Avaliações negativas & 25 \\
\hline & \multirow{3}{*}{$\begin{array}{l}\text { Diagnóstico } \\
\text { de problemas }\end{array}$} & Problemas dos alunos & 18 \\
\hline & & Interação de sala de aula & 06 \\
\hline & & Problemas do professor & 12 \\
\hline & \multirow{3}{*}{$\begin{array}{c}\text { Soluções de } \\
\text { problemas }\end{array}$} & Formas alternativas & 11 \\
\hline & & Plano de ção & 13 \\
\hline & & Formas de buscar ajuda & 08 \\
\hline \multirow{6}{*}{ 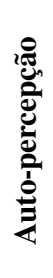 } & \multirow{3}{*}{$\begin{array}{c}\text { Percepções } \\
\text { de si }\end{array}$} & Estilo de ensinar & 28 \\
\hline & & Estilo de aprender & 09 \\
\hline & & Proficiência na língua & 09 \\
\hline & Crescimento pessoal & Como a pesquisa ajudou & 13 \\
\hline & \multirow{2}{*}{$\begin{array}{l}\text { Objetivos } \\
\text { pessoais }\end{array}$} & Auto-desenvolvimento & 31 \\
\hline & & Planos para o futuro & 05 \\
\hline & & Total & 582 \\
\hline
\end{tabular}

